\title{
Psychometric properties of the Arabic version of the Activities-Specific Balance Confidence (ABC) scale in ambulatory, community-dwelling, elderly people
}

This article was published in the following Dove Press journal:

Clinical Interventions in Aging

\author{
Michal Elboim-Gabyzon' \\ Maayan Agmon ${ }^{2}$ \\ Faisal Azaiza ${ }^{3}$ \\ 'Physical Therapy Department, Faculty of \\ Social Welfare and Health Sciences, \\ University of Haifa, Haifa, Israel; \\ ${ }^{2}$ Department of Nursing, Faculty of Social \\ Welfare and Health Sciences, University \\ of Haifa, Haifa, Israel; ${ }^{3}$ School of Social \\ Work, Faculty of Social Welfare and \\ Health Sciences, University of Haifa, \\ Haifa, Israel
}

\begin{abstract}
Background: Fear of falling (FOF) is common among elderly individuals and can appear independently of a previous fall. FOF can start a vicious cycle by leading to a sedentary lifestyle and further FOF, with negative physical and mental consequences. The ActivitiesSpecific Balance Confidence (ABC) scale is a popular, theoretically based, reliable and valid tool designed to assess FOF in ambulatory, community-dwelling, elderly people. A balance confidence measurement tool for Arabic-speaking ambulatory, community-dwelling, elderly individuals is lacking. The objective of the present study was to translate and culturally adapt the $\mathrm{ABC}$ to Arabic and to determine its psychometric properties in ambulatory, communitydwelling elderly people.
\end{abstract}

Materials and methods: This two-stage exploratory study included a forward and backward translation process and the administration of the Arabic ABC (A-ABC) via face-to-face interviews. In addition, performance-based clinical measures of balance were assessed, and two self-report physical function and disability questionnaires were administered. The study included 60 volunteers (34 women), with a mean age of $74.1 \pm 6.23$ years, recruited from the Arab population of northern Israel. To determined test-retest reliability, the questionnaire was re-administered to 40 of the 60 participants twice at a 6-8-day interval.

Results: One of the $16 \mathrm{~A}-\mathrm{ABC}$ scale items was modified to adjust for local climate. The main results included high internal consistency (Cronbach's $\alpha=0.97$ ), good to excellent structural coherence (corrected item-total correlation: 0.77-0.92); excellent test-retest reliability ( $\mathrm{ICC}=0.98$, confidence interval $=0.08-3.05$ ); low standard error of measure and low smallest real difference ( $3.5 \%$ and $9.64 \%$, respectively); strong-to-moderate correlations with performance-based clinical measures of balance and self-report physical function and disability questionnaires; and a ceiling effect. A significant difference between genders and between fallers and non-fallers was demonstrated.

Conclusions: The A-ABC demonstrated excellent psychometric properties in elderly, Arabic-speaking, independently living individuals and can be used as a balance confidence measurement tool in research and clinical settings.

Keywords: reliability, validity, Arabic, balance confidence, elderly

\section{Introduction}

The risk for falls increases with age, with dire consequences for the individual and society at large. ${ }^{1}$ While the causes of falls among elderly individuals are
Correspondence: Michal Elboim-Gabyzon Social Welfare and Health Sciences, University of Haifa, Balfour 9 Nahariya, Haifa 2242I, Israel

Tel +972545968943; +9720482880

Email Michal.elboim@gmail.com 
multifactorial, the analysis of these causes, by using, for example, sensor technology, is essential for the prediction and prevention of falls. ${ }^{2}$ Elderly individuals often report a fear of falling (FOF), which is one factor increasing the risk of falling. ${ }^{3}$ The reported incidence of FOF ranges from $20 \%$ to $85 \%{ }^{4,5}$ FOF is not necessarily the result of psychological trauma due to a previous fall, ${ }^{6}$ but can appear independently of a previous fall. ${ }^{7,8}$ FOF can start a vicious cycle comprised of a sedentary lifestyle, with negative physical and mental consequences related to functional decline, decreased lower extremity strength and depression, ${ }^{8,9}$ which in turn affect the quality of life and reduce participation. ${ }^{10}$ Although falling and FOF may share causes and risk factors, their assessment, prevention and treatment should be addressed separately.

FOF can be assessed by several measures. ${ }^{4}$ The Activities-Specific Balance Confidence (ABC) scale, ${ }^{11}$ based on Bandura's concept of self-efficacy, ${ }^{12}$ was designed to assess FOF in ambulatory, community-dwelling, elderly people. It is the most frequently used self-reported assessment tool. ${ }^{11}$ The ABC assesses self-efficacy in performing tasks of varying difficulty, including those performed outdoors. It is composed of 16 items rated on an ordinal scale ranging from zero (representing no confidence) to 100 (representing complete confidence). The total score $(0-1,600$ possible) is recorded as a percentage, with lower scores indicating lower levels of balance confidence, which are related to balance impairment and falls. ${ }^{13}$

The ABC scale is popular due to its high psychometric quality and its firm theoretical basis. It is simple to perform, in that it requires minimal training and no equipment. It is relatively quick to administer (10-20 mins) and can be administered during a face-to-face interview or can be completed as a self-report by the individual subject. Accordingly, its use as a valid and reliable assessment tool was extended to various pathologies, including Parkinson's disease, stroke, multiple sclerosis, amputation and vestibular disorders. ${ }^{14,15}$ The ABC has been successfully translated and culturally adapted for several languages, including Chinese, Swedish and Canadian French, ${ }^{15-19}$ thus enabling the establishment of a balance confidence database that includes culturally and linguistically diverse populations. ${ }^{17}$

Arabic is ranked as the fifth most widely spoken languages in the world, used by as many as 420 million people. $^{20,21}$ Its use is expected to increase and is not confined to the borders of Arab countries. ${ }^{20}$
The reliability and validity of the Arabic translation of the ABC (A-ABC) was demonstrated in Jordan and Saudi Arabia among 82 Arabic-speaking participants (mean age 43 years) with peripheral or central vestibular disorders. ${ }^{22}$ However, there is a lack of evidence of the psychometric proprieties of the A-ABC among the population of ambulatory, community-dwelling, elderly people, for whom the scale was originally developed.

The aim of the current study was to translate and culturally adapt the $\mathrm{ABC}$ to Arabic and to ascertain the psychometric properties of the translated version.

\section{Materials and methods}

This study is part of a larger study that included translation and culturally adaption of the Late-Life Function and Disability Instrument (LLFDI) to Arabic. ${ }^{23}$

The ABC was translated according to accepted forward and backward translation guidelines. ${ }^{24} \mathrm{~A}$ bilingual physical therapist, familiar with the $\mathrm{ABC}$ and a professional translator (native Arabic-speaking) independently translated the ABC from English into literary Arabic. The two Arabic versions were compared in a group discussion with five bilingual physical therapists treating the elderly. Two new bilingual translators independently performed the next stage of back translation into English. Finally, the two researchers (MEG and MA) reached consensus on the accuracy of the version translated back into English. Question 16, "walk outside on icy sidewalks", was changed to "walk outside on slippery sidewalks" due to Israel's climate, as snow is extremely rare.

The final Arabic version was piloted with ten community-dwelling elderly people. They were asked to report whether the questions were understandable, appropriate and relevant to their daily function. The participants agreed that all the questionnaire items met these criteria.

Participants for the study were recruited by snowball sampling from two rural and one urban community centers. Following an explanation of the study goals and procedures, all subjects provided signed informed consent prior to participation.

The sample was composed of 60 elderly people from the Arab population of Israel. The inclusion criteria were community-dwelling individuals 65 years of age or older; ability to walk independently without a walking aid; no major orthopedic or other medical condition affecting independence or balance capabilities; ability to understand simple commands; and no serious uncorrected visual or hearing deficits. 
Sociodemographic data were collected from each subject using a standardized interview protocol that included subject characteristics (age, gender, religion, number of children, family status), health-related information, and fallrelated information (FOF [yes/no], number of falls in the last year, and self-reported activity limitations due to FOF [yes/no]).Questions included in the interview were chosen based on clinical experience and on the literature. ${ }^{23,24}$

The A-ABC was administered via face-to-face interviews, as recommended by the developer of the scale. ${ }^{11}$ Test-retest reliability was evaluated among 40 of the 60 participants by readministering the questionnaire $6-8$ days later. This time frame was chosen to minimize the recall of the answers from the initial assessment and to avoid variations in clinical status. In addition, the subjects were asked to report any changes that might have affected their responses to the questionnaire.

Construct validity was assessed by correlating the responses to the $\mathrm{A}-\mathrm{ABC}$ to two questionnaires relating the individuals' own perceptions of their functionality and health status (the LLFDI and the SF-36), and to two performance-based clinical measures of dynamic balance (the Timed Up and Go test (TUG) and the Berg Balance Scale (BBS). The sequence of the examinations was constant: A-ABC, two SF-36 subscales, LLFDI, BBS and TUG test. Following is a brief description of these measures.

The LLFDI translated to Arabic ${ }^{23}$ is a validated, selfreport questionnaire designed specifically to assess physical function and disability in community-dwelling elderly adults. ${ }^{23}$ It is comprised of function and disability sections, with the disability component including two dimensions (limitation and frequency). Each item is scored on 1-5 point Likert scale, and the overall raw scores and the scores of each component were transformed to scaled scores $(0-100)$ in accordance with the score tables based on a Rasch analysis model provided by the Royal Center for Enhancement of Late-Life Function. ${ }^{25}$

The Arabic version of the Physical Function component (PF) and the Physical Component (PCS) of the Short Form General Health Survey (SF-36) questionnaire are validated tools frequently used as self-report measures of health. ${ }^{26}$ The PF includes items focusing on three main attributes of physical function: self-care, mobility, and body movement. The PCS includes the PF, physical role, pain and general health subscales of the SF-36. Lower scores indicate more disability, and higher scores, less disability (range $0-100){ }^{26}$

The TUG is a validated and reliable test for assessing balance during mobility among community-dwelling adults. It measures the time required to rise from a straight chair, walk $3 \mathrm{~m}$, turn around, walk back to the chair and sit down safely. Scores of less than $20 \mathrm{~s}$ were demonstrated to be an indication of independence in basic transfers among community-dwelling elderly people. ${ }^{27}$

The BBS assesses balance ability in adult populations with 14 static and dynamic tasks of varying difficulty. Item scores are summed, with a maximum score of 56; higher scores indicate better performance. Scores of 45 or more indicate functional ability. ${ }^{28}$

Discriminative validity was assessed by comparing the A-ABC scores between men and women and between fallers (defined as one or more falls within the previous year) and non-fallers.

\section{Ethics approval and consent to participate}

The study was approved by the Institutional Review Board of the Faculty of Social Welfare and Health Sciences at the University of Haifa.

\section{Statistical analysis}

Analysis of descriptive data included means and SD, counts and percentages, as appropriate.

Internal consistency was determined by Cronbach's alpha coefficient and item-total correlations (index "alpha if item deleted" and "Corrected Item-Total Correlation"), with $\alpha$ values $\geq 0.9$ considered excellent, $0.7 \leq \alpha<0.9$ considered good, $0.6 \leq \alpha<0.7$ considered acceptable, $0.5 \leq \alpha<$ 0.6 considered poor and values of $\alpha<0.5$ unacceptable. ${ }^{29,30}$ Values of corrected item-total correlations from 0.30 to 0.70 were considered to be good in accordance with the recommendation of Ferketich. ${ }^{30}$ Test-retest reliability was determined with $\mathrm{ICC}_{2,1}$ and classified according to Bland and Altman $_{\text {criteria }^{31}}(\leq 0.20$ poor, $0.21-0.40$ fair, $0.41-0.60$ moderate, $0.61-0.80$ good, and $0.81-1.00$ very good) ${ }^{31}$ Bland-Altman plots were used to compare measures of the A-ABC total score between the first test and retest. ${ }^{32}$ Absolute reliability was analyzed by the standard error of measure (SEM) and by the smallest real difference (SRD). ${ }^{33}$ Structural coherence was demonstrated by exploratory factor analysis, with the minimum value of 0.60 recommended by Kaser Meyer Oklin as acceptable. ${ }^{18}$

Construct validity of the $\mathrm{ABC}$ was determined using Pearson correlations with the two SF-36 subscales, LLFDI, BBS and TUG test. Pearson correlation coefficients above 0.75 indicate a strong correlation, and values 
ranging from 0.50 to 0.75 represent a moderate correlation. $^{34}$ Discriminant validity between genders, fallers and non-fallers was examined using two-sample t-tests

Floor and ceiling effects were determined by calculating the percentage of respondents who received the minimum and maximum possible scores, respectively. According to previous reports, the percentages should not exceed $15 \% .^{35}$ Statistical analyses were performed using SAS version 9.4 (SAS Institute, Cary, NC, USA).

\section{Results}

The study sample included 60 volunteers (26 men and 34 women), at a mean age of $74.1 \pm 6.23$ years. Table 1 describes their demographic characteristics. Among the sample, 33 (55\%) reported that they have FOF (yes/no question) and $24(40 \%)$ reported limitations in activity due to FOF. The results of the LLFDI, SF-36 PCS, PF and the performancebased clinical measures of balance are presented in Table 2 .

Table I Demographic characteristics of the study sample $(n=60)$

\begin{tabular}{|l|l|}
\hline Characteristic & \\
\hline Age, mean \pm SD, range & $74.1 \pm 6.23$, \\
& $65-88$ \\
\hline Gender, $n$ (\%) & \\
Men & $26(43.3 \%)$ \\
Women & $34(56.7 \%)$ \\
\hline Religion, n (\%) & \\
Christian & $25(41.7 \%)$ \\
Moslem & $17(28.3 \%)$ \\
Druze & $18(30.0 \%)$ \\
\hline Number of children, mean \pm SD, range & $5.85 \pm 3.08$, \\
& $0-12$ \\
\hline Family status, $n$ (\%) & \\
\hline Married & $40(66.7 \%)$ \\
Widowhood & $17(28.3 \%)$ \\
Not married & $3(5.0 \%)$ \\
\hline Height, cm, mean \pm SD, range & $160.87 \pm 10.38$, \\
& $140-184$ \\
\hline Weight, kg, mean \pm SD, range & $75.78 \pm 12.96$, \\
& $44-106$ \\
\hline Body mass index (BMI), kg/cm ${ }^{2}$, mean \pm SD, range & $29.47 \pm 5.61$, \\
& $19.56-44.28$ \\
\hline Numge & $1.65 \pm 1.19,0-4$ \\
\hline Number of diagnosed diseases, mean \pm SD, range & $3.12 \pm 2.6,0-10$ \\
\hline Number of prescribed medications, mean \pm SD, & $1.33 \pm 1.32,0-5$ \\
\hline
\end{tabular}

Table 2 Results of subjective and objective measures

\begin{tabular}{|l|l|}
\hline $\begin{array}{l}\text { Late-Life Function and Disability } \\
\text { Instrument }\end{array}$ & Mean \pm SD; Range \\
\hline Function component: total & $62.03 \pm 16.34 ; 26.33-100$ \\
Disability component: & \\
Frequency total & $45.37 \pm 11.62 ; 22.64-100$ \\
Limitation total & $69.96 \pm 22.9 ; 33.64-100$ \\
\hline SF-36 & \\
Physical component score (SF-36), 0-400 & $241.78 \pm 107.9 ; 42.5-395$ \\
Physical functioning subscale, 0-100 & $61.87 \pm 30.44 ; 5-100$ \\
\hline Performance tests & \\
Time Up and Go test, sec & $15.13 \pm 7.34 ; 7.01-41.63$ \\
Berg Balance Scale, 0-56 & $43.52 \pm 12.45 ; 10-56$ \\
\hline
\end{tabular}

Note: SF-36=36-Item Short Form Survey.

High internal consistency was demonstrated for the total A-ABC score, with Cronbach's $\alpha=0.976$. This was reinforced by moderate-to-strong item-total correlations for all 16 items, ranging from 0.77 to 0.92 , and exceeding the recommended cutoff value of $0.7 .^{30}$ Further analysis deleting each item supported retaining all 16 items (Table 3). ${ }^{18}$

Very good test-retest reliability of the A-ABC was found, as reflected by an ICC of 0.98 (95\% CI 0.08-3.05) presented in Table 4. The ICC per item ranged from 0.82 to 0.96 , with the highest related to items 7 ("sweep the floor?") and 14 ("step onto or off of an escalator while you are holding onto a railing"). ${ }^{11}$ The lowest ICC was for item 16 ("walk outside

Table 3 Internal consistency of the Arabic translation of the $A B C(A-A B C)$ scale

\begin{tabular}{|l|l|l|}
\hline $\begin{array}{l}\text { Number of } \\
\text { items }\end{array}$ & $\begin{array}{l}\text { Corrected item-total } \\
\text { correlation }\end{array}$ & $\begin{array}{l}\text { Alpha, if item } \\
\text { deleted }\end{array}$ \\
\hline $\mathbf{I}$ & 0.77 & 0.976 \\
$\mathbf{2}$ & 0.92 & 0.974 \\
$\mathbf{3}$ & 0.83 & 0.975 \\
$\mathbf{4}$ & 0.81 & 0.975 \\
$\mathbf{5}$ & 0.86 & 0.975 \\
$\mathbf{6}$ & 0.90 & 0.974 \\
$\mathbf{7}$ & 0.83 & 0.975 \\
$\mathbf{8}$ & 0.85 & 0.975 \\
$\mathbf{9}$ & 0.85 & 0.975 \\
$\mathbf{1 0}$ & 0.82 & 0.975 \\
$\mathbf{I I}$ & 0.91 & 0.974 \\
$\mathbf{I 2}$ & 0.92 & 0.974 \\
$\mathbf{1 3}$ & 0.92 & 0.974 \\
$\mathbf{1 4}$ & 0.80 & 0.976 \\
$\mathbf{1 5}$ & 0.89 & 0.974 \\
$\mathbf{1 6}$ & 0.85 & 0.975 \\
\hline
\end{tabular}

Note: Cronbach's- $\alpha$ coefficient of ABC-C scale equal to 0.976 . 
Table 4 Psychometric properties of the Arabic translation of the $A B C(A-A B C)$ scale

\begin{tabular}{|l|l|l|l|l|l|l|l|l|l|l|l|}
\hline \multirow{2}{*}{ Parameter } & \multicolumn{2}{|l|}{ Mean } & $\begin{array}{l}\text { Mean dif- } \\
\text { ference }\end{array}$ & $\begin{array}{l}\text { Lower 95\% CI } \\
\text { mean difference }\end{array}$ & $\begin{array}{l}\text { Upper 95\% CI } \\
\text { Ist }\end{array}$ & 2nd & ICC (2.1) & SEM & $\begin{array}{l}\text { SEM } \\
\%\end{array}$ & $\begin{array}{l}\text { SRD } \\
\text { SRD } \\
\%\end{array}$ & $\begin{array}{l}\text { Cronbach's } \\
\text { alpha }\end{array}$ \\
\hline $\begin{array}{l}\text { A-ABC } \\
\text { score }\end{array}$ & 68.65 & 77.55 & 1.56 & 0.08 & 3.05 & 0.978 & 3.48 & 4.58 & 9.64 & 12.68 & 0.976 \\
\hline
\end{tabular}

Abbreviations: $A-A B C$, Arabic translation of the $A B C$ scale; ICC, intra-class correlation coefficient; SEM, the standard error of measure; SRD, smallest real difference

on slippery sidewalks"). The Bland-Altman Plot for A-ABC total score, shown in Figure 1, illustrates no bias, with all but three data points lying within the $95 \%$ limits of agreement.

Absolute reliability showed that the SEM at the group level was $3.48(4.58 \%)$. The SRD at the individual level was 9.64 (12.68\%) (Table 4).

Structural coherence was demonstrated by exploratory factor analysis, with the minimum value of 0.60 recommended by Kaser Meyer Oklin as acceptable. ${ }^{18}$ All the 16 items demonstrated high loadings, which ranged from 0.79 to 0.92 with $74 \%$ of the total variance explained and an eigenvalue of 11.83 (Table 5).

${ }^{18}$ The A-ABC score demonstrated strong-to-moderate positive correlations with the two components of the
LLFDI (function component $\mathrm{r}=0.83$; limitation dimension of disability component $\mathrm{r}=0.85$; and frequency dimension of disability components $\mathrm{r}=0.70 ; p<0.0001$ ). Moderate positive correlations were found with the two parts of the SF-36 (PCS $\mathrm{r}=0.68$; PF $\mathrm{r}=0.65, p<0.0001$ ). Strong-tomoderate correlations were noted with the $\mathrm{A}-\mathrm{ABC}$ and the performance-based clinical measures of balance (BBS $\mathrm{r}=0.86$ and TUG $\mathrm{r}=-0.69, p<0.0001$ ) (Table 6).

The sample included 27 fallers (55\%) and 33 non-fallers (55\%), with the number of falls ranging from 1 to 6 in the year preceding data collection. A significant difference in the mean A-ABC score was found between fallers and non-fallers, with non-fallers demonstrating higher balance confidence as compared to fallers ( $77.5 \pm 24.8$ vs $57.8 \pm 27.2$,

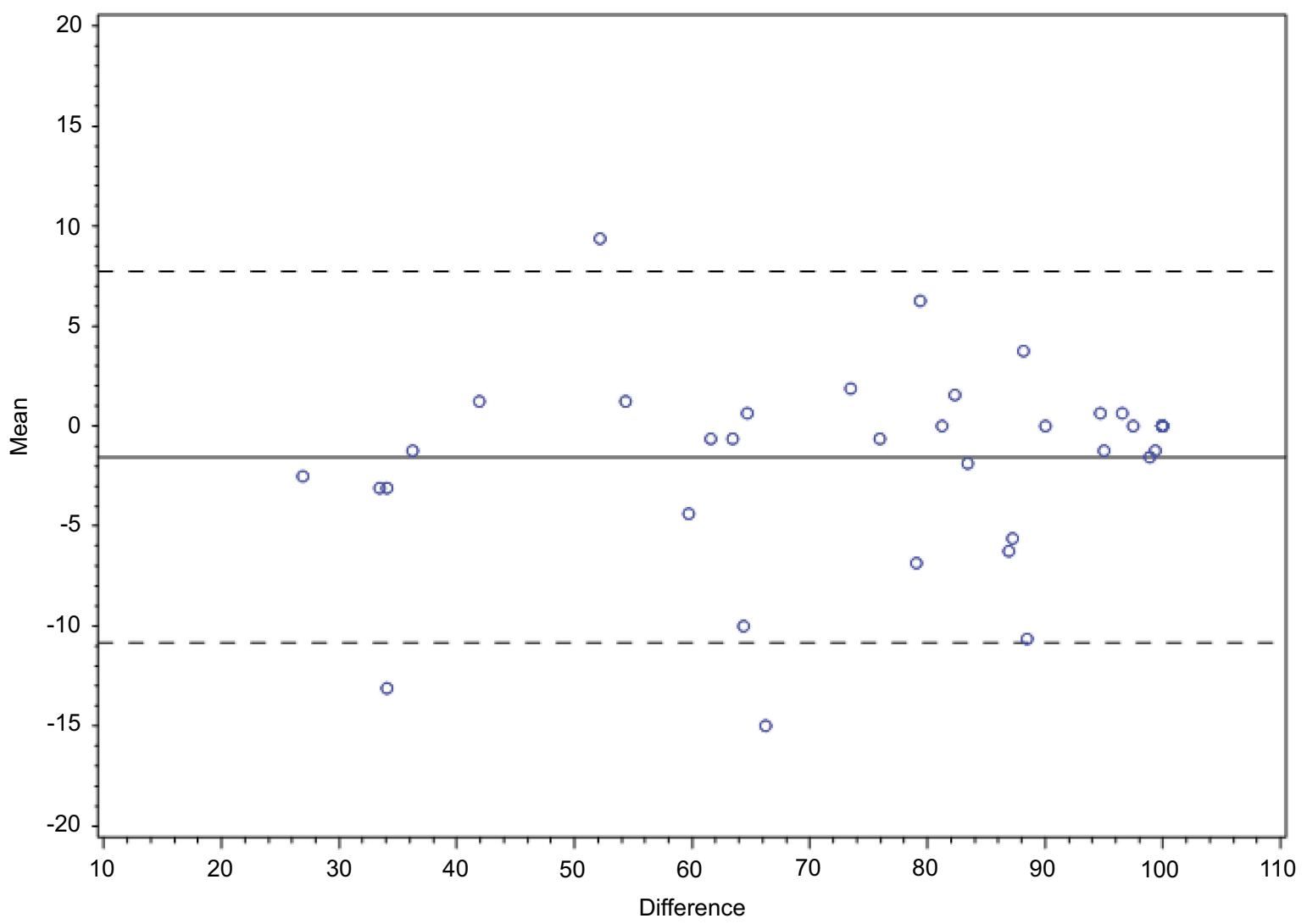

Figure I Bland-Altman plots for Arabic translation of the Activities SpecificActivities-Specific Balance Confidence scale total score. 
Table 5 Mean value for test-retest, $95 \%$ confidence interval $(95 \% \mathrm{Cl})$, intra-class correlation coefficient $\left(\mathrm{ICC}_{2.1}\right)$, and factor analysis of each question in the Arabic translation of the $A B C(A-A B C)$ scale

\begin{tabular}{|c|c|c|c|c|c|c|}
\hline \multirow[t]{2}{*}{ Number of item } & \multicolumn{2}{|l|}{ Mean } & \multicolumn{2}{|c|}{ 95\% Cl mean difference } & \multirow[t]{2}{*}{ ICC (2.1) } & \multirow[t]{2}{*}{ Factor analysis } \\
\hline & Ist & 2nd & Lower & Upper & & \\
\hline I & 85.17 & 91.25 & 0.89 & 0.97 & 0.94 & 0.79 \\
\hline 2 & 70.33 & 78.50 & 0.91 & 0.97 & 0.95 & 0.92 \\
\hline 3 & 70.50 & 75.50 & 0.75 & 0.92 & 0.86 & 0.83 \\
\hline 4 & 82.83 & 89.50 & 0.75 & 0.92 & 0.86 & 0.82 \\
\hline 5 & 54.00 & 61.25 & 0.91 & 0.97 & 0.95 & 0.85 \\
\hline 6 & 51.67 & 63.25 & 0.91 & 0.97 & 0.95 & 0.89 \\
\hline 7 & 76.50 & 84.75 & 0.93 & 0.98 & 0.96 & 0.84 \\
\hline 8 & 84.00 & 90.25 & 0.86 & 0.96 & 0.92 & 0.86 \\
\hline 9 & 83.67 & 91.25 & 0.80 & 0.94 & 0.89 & 0.86 \\
\hline 10 & 72.17 & 82.25 & 0.79 & 0.93 & 0.88 & 0.83 \\
\hline II & 63.50 & 73.25 & 0.75 & 0.92 & 0.86 & 0.91 \\
\hline 12 & 67.33 & 77.88 & 0.84 & 0.95 & 0.91 & 0.92 \\
\hline 13 & 58.17 & 69.00 & 0.91 & 0.97 & 0.95 & 0.91 \\
\hline 14 & 71.50 & 81.50 & 0.93 & 0.98 & 0.96 & 0.80 \\
\hline 15 & 55.00 & 63.50 & 0.86 & 0.96 & 0.92 & 0.88 \\
\hline 16 & 52.00 & 67.88 & 0.69 & 0.90 & 0.82 & 0.83 \\
\hline
\end{tabular}

Table 6 Significant results of the pearson analysis $(p<0.001)$

\begin{tabular}{|l|l|l|l|l|l|l|l|}
\hline & \multicolumn{2}{|l|}{ LLFDI } & \multicolumn{2}{l|}{ SF-36 } & \multicolumn{2}{l|}{ Performance Tests } \\
\cline { 2 - 6 } & \multirow{2}{*}{ Function Component-Total } & \multicolumn{2}{|l|}{ Disability Component } & \multirow{2}{*}{ PCS } & \multirow{2}{*}{ PF } & BBS & TUG \\
\cline { 2 - 5 } & & Frequency Total & Limitation Total & & & & \\
\hline ABC Total score & 0.83 & 0.70 & 0.85 & 0.68 & 0.65 & 0.86 & -0.69 \\
\hline
\end{tabular}

Abbreviations: LLFDI, Late-Life Function and Disability Instrument; SF-36, 36-Item Short Form Survey; PCS, Physical Component Score; PF, Physical Functioning Subscale of Physical Component Score; BBS, Berg Balance Scale; TUG, Time Up and Go test.

$p=0.005$ ) (Table 7). Fallers also had poorer balance performance scores and self-reported health and functional performance than did non-fallers (Table 7).

A gender-related difference was demonstrated for the $\mathrm{A}-\mathrm{ABC}$ score, with men presenting higher balance confidence compared to women $(76.6 \pm 22.7$ vs $62.6 \pm 29.6$, respectively; $p=0.05)$. Gender was also related to FOF, when it was asked as a dichotomous question, with $10(38 \%)$ men, as compared to $23(68 \%)$ women responding they have a FOF $(p=0.024)$. Additionally, fall status was gender-related, with $22(65 \%)$ women compared to $5(19 \%)$ men reporting a fall $(p<0.001)$.

Finally, a ceiling effect was noted for the A-ABC with 9 subjects (15\%) scoring 100 . No floor effect was noted, as none of the subjects scored 0 .

\section{Discussion}

This study explored the psychometric properties of the $\mathrm{ABC}$ instrument following its translation into Arabic, which was administered to Arabic-speaking elderly individuals living in communities in northern Israel.

The excellent internal consistency $(\alpha=0.976)$ demonstrated is comparable with the results reported by Powell and Myers for the original English-language version, tested in North America $(\alpha=0.96),{ }^{11}$ as well as with the modified version adjusted for an elderly British population $(\alpha=0.98) .{ }^{19}$ It also compares well with versions translated into Chinese and Mandarin Chinese ( $\alpha=0.94,0.97$, respectively) ${ }^{15,18}$

The A-ABC exhibited excellent test-retest reliability ( $\mathrm{ICC}=0.99$ ), similar to the values reported for the Chinese and the Mandarin Chinese versions ( $\mathrm{ICC}=0.98 ; \alpha=0.92$ ), and slightly higher than that reported for the original English version $(\alpha=0.89){ }^{11,19}$

The relatively low SEM and SRD (3.48\% and 9.64\%, respectively) suggest reasonably high inter-test precision, a prerequisite for sensitivity to individual or group changes 
Table 7 Comparison between the results of A-ABC scale, demographic characteristics, subjective and objective measures between fallers and no fallers (mean $( \pm)$ standard deviation and $p$-value)

\begin{tabular}{|c|c|c|c|}
\hline & \multicolumn{3}{|l|}{ Fall status } \\
\hline & Fallers $(n=27)$ & No fallers $(n=33)$ & $p$-Value \\
\hline A-ABC score & $57.82 \pm 27.2$ & $77.5 \pm 24.79$ & 0.005 \\
\hline Age, years & $74.1 \pm 5.4$ & $74.0 \pm 6.9$ & 0.91 \\
\hline BMI, $\mathrm{kg} / \mathrm{cm} 2$ & $30.5 \pm 6.2$ & $28.6 \pm 5.1$ & 0.2 \\
\hline \multicolumn{4}{|c|}{ Late-Life Function and Disability Instrument } \\
\hline $\begin{array}{l}\text { Function component-total } \\
\text { Disability component: } \\
\text { Frequency total } \\
\text { Limitation total }\end{array}$ & $\begin{array}{l}56.15 \pm|4.5| \\
41.72 \pm 8.22 \\
61.65 \pm 22.11\end{array}$ & $\begin{array}{l}66.5 \pm 16.27 \\
48.56 \pm 13.04 \\
77.44 \pm 21.57\end{array}$ & $\begin{array}{l}0.01 \\
0.02 \\
0.007\end{array}$ \\
\hline $\begin{array}{l}\text { SF-36 } \\
\text { Physical component score, } 0-400 \\
\text { Physical functioning subscale, } 0-100\end{array}$ & $\begin{array}{l}194.44 \pm 101.29 \\
49.26 \pm 30.5\end{array}$ & $\begin{array}{l}280.52 \pm 98.44 \\
72.18 \pm 26.62\end{array}$ & $\begin{array}{l}0.01 \\
0.03\end{array}$ \\
\hline $\begin{array}{l}\text { Performance Tests } \\
\text { Time Up and Go test, sec } \\
\text { Berg Balance Scale, } 0-56\end{array}$ & $\begin{array}{l}16.26 \pm 7.6 \\
39.07 \pm \mid 2.91\end{array}$ & $\begin{array}{l}13.68 \pm 0.7 .47 \\
47.15 \pm 10.95\end{array}$ & $\begin{array}{l}0.1 \\
0.01\end{array}$ \\
\hline
\end{tabular}

Abbreviations: A-ABC, Arabic translation of the ABC Scale; BMI, Body mass index; SF-36, 36-Item Short Form Survey.

over time. This value was slightly higher than that observed with other community-dwelling elderly people (SEM of 2.45), ${ }^{36}$ but lower than that observed in Parkinson's and stroke populations (SEM of 4.01 and 6.81 , respectively). ${ }^{14,37}$ These differences might be attributed to variations in the severity of comorbidities among the populations evaluated.

Construct validity was demonstrated by strong-tomoderate correlations between the A-ABC and subjective self-reported tools, as well as by objective, clinically assessed balance measures. Thus, as previously demonstrated, significant, moderately positive correlations were observed between the A-ABC and both parts of the SF-36 (PCS $\mathrm{r}=0.68$; PF $\mathrm{r}=0.65, p<0.0001$ ), as well as with the LLFDI. $^{38}$ These associations were expected, as they support the concept that there is an overlap between FOF, health status, functional ability and disability in community-dwelling elderly adults. The strongest correlation was demonstrated between the A-ABC and the BBS $(\mathrm{r}=0.86$, $p<0.0001$ ), which was supported by the negative correlation between the A-ABC and the TUG $(\mathrm{r}=-0.7, p<0.01)$. These results, which are compatible with those of Hatch et al. ${ }^{39}$ among English-speaking, community-dwelling elderly people, confirms a strong association between actual and perceived balance ability among community-dwelling elderly people. It does not, however, resolve the dilemma of whether decreased balance ability results in FOF or vice versa.

The current study identified an average level of selfperceived balance confidence, as assessed by the A-ABC, of $68.65( \pm 27.51)$ in elderly Arab community-dwellers in northern Israel. This result is in accordance with those reported for community-dwelling elderly in Hong Kong (71.6 \pm 23.7$)$ and in India (average $=71$, range 41.25-95.63). ${ }^{18,36,40}$ However, the current result was lower than the $\mathrm{ABC}$ score reported by Hatch et $\mathrm{al}^{39}$ among elderly people in the greater Boston area (78.87 $\pm 19.1)$ and in Brazil $(81.7 \pm 10.1),{ }^{40}$ but higher than the score reported by Powell and Myers ${ }^{11}$ in a Canadian population (59.6 \pm 17.7$)$. These differences might be explained by variations in the populations studied and reflect that balance confidence is a multifactorial construct which can be influenced by factors such as age, gender, physical activity status, general health, sensory, balance and motor dysfunction, fall history and socioeconomic status. ${ }^{39}$

The A-ABC demonstrated discriminative validity between fallers and non-fallers, with fallers demonstrating lower scores. The values of the A-ABC in the current study were lower than the cutoff score of $<67 \%$, suggested by Lajoie and Gallagher, ${ }^{13}$ indicating a risk for falling. In addition, fallers demonstrated lower balance performance compared to non-fallers, congruent with the established cutoff scores for these tests. ${ }^{28,41}$ 
Higher balance confidence in men compared to women was demonstrated, which was in accordance with previous studies demonstrating gender-related balanced confidence. ${ }^{42}$ Accordingly, screening and identifying elderly adults with FOF should also be tailored to the gender of the individual.

No floor effect was observed in the current study, while a ceiling effect was observed, as $15 \%$ of the scores were extreme $(100 \%)$. This contrasts with some previous studies. ${ }^{19,36}$ We speculate that this too is related to the sample's specific socioeconomic and cultural characteristics, might also explain the discrepancy between the results of average $\mathrm{A}-\mathrm{ABC}$ scores and the fact that none of the participants used an assistive device. Further research is necessary to elucidate these points.

Some limitations of the study should be noted. While inclusion criteria indicated that subjects did not have a major neurologic or medical condition that could affect their independence and balance capabilities, given the fact that $55 \%$ indicated falling at least once in the previous year, one cannot exclude the possibility that the balance of some was somewhat compromised either by an undiagnosed medical condition (eg neuropathy) or by the medication they used. Furthermore, the study sample consisted of Arabicspeaking, community-dwelling elderly people residing in Israel. Thus, in order to enhance the generalizability of the data, future studies should include participants from other Arab countries. Also needed are studies which include community-dwelling elderly people who use assistive devices for ambulation. Finally, the sample was heterogeneous in terms of age, severity of comorbidities, socioeconomic and psychosocial and health-related factors, which could have affected the results.

In conclusion, the $\mathrm{ABC}$ instrument, translated into Arabic and tested in community-dwelling elderly people, demonstrated excellent psychometric properties comparable to the original English version. It can thus be used as a balance confidence measurement tool for Arabicspeaking, elderly individuals.

\section{Abbreviations list}

FOF, fear of falling; ABC, Activities-Specific Balance Confidence scale; A-ABC, Arabic translation of the Activities-Specific Balance Confidence scale; LLFDI, LateLife Function and Disability Instrument; MEG, Michal Elboim-Gabyzon; MA, Maayan Agmon; PF, Arabic version of the Physical Function component of the Short Form General Health Survey questionnaire; PCS, Physical Component of the Short Form General Health Survey questionnaire; SF-36, Short Form General Health Survey questionnaire; TUG, Timed Up and Go test; BBS, Berg Balance Scale; SD, standard deviations; ICC, intra-class correlation coefficient; SEM, standard error of measure; SRD, smallest real difference; CI, confidence interval; $n$, number; cm, centimeter; kg, kilograms; BMI, body mass index.

\section{Data sharing statement}

The dataset used and analyzed during the current study is available from the corresponding author on reasonable request.

\section{Acknowledgments}

This research did not receive any specific grant from funding agencies in the public, commercial, or not-forprofit sectors.

\section{Author contributions}

All authors contributed to data analysis, drafting and revising the article, gave final approval of the version to be published, and agree to be accountable for all aspects of the work.

\section{Disclosure}

The authors report no conflicts of interest in this work.

\section{References}

1. Khow KS, Visvanathan R. Falls in the aging population. Clin Geriatr Med. 2017;33(3):357-368. doi:10.1016/j.cger.2017.03.002

2. Rucco R, Sorriso A, Liparoti M, et al. Type and location of wearable sensors for monitoring falls during static and dynamic tasks in healthy elderly: a review. Sensors. 2018;18(5):1613. doi:10.3390/s18051613

3. Rossat A, Fantino B, Nitenberg C, et al. Risk factors for falling in community-dwelling older adults: which of them are associated with the recurrence of falls? J Nutr Health Aging. 2010;14(9):787-791. doi:10.1007/s12603-010-0089-7

4. Scheffer AC, Schuurmans MJ, Van Dijk N, Van Der Hooft T, De Rooij SE. Fear of falling: measurement strategy, prevalence, risk factors and consequences among older persons. Age Ageing. 2008;37 (1):19-24. doi:10.1093/ageing/afm169

5. Zijlstra G, Van Haastregt J, Van Eijk JTM, van Rossum E, Stalenhoef PA, Kempen GI. Prevalence and correlates of fear of falling, and associated avoidance of activity in the general population of community-living older people. Age Ageing. 2007;36(3):304-309. doi:10.1093/ageing/afm021

6. Murphy J, Isaacs B. The post-fall syndrome. Gerontology. 1982;28 (4):265-270. doi:10.1159/000212543

7. Lawrence RH, Tennstedt SL, Kasten LE, Shih J, Howland J, Jette AM. Intensity and correlates of fear of falling and hurting oneself in the next year: baseline findings from a roybal center fear of falling intervention. J Aging Health. 1998;10(3):267-286. doi:10.1177/ 089826439801000301 
8. Litwin H, Erlich B, Dunsky A. The complex association between fear of falling and mobility limitation in relation to late-life falls: a share-based analysis. J Aging Health. 2017;0898264317704096.

9. Choi K, Jeon G-S, Cho S-i. Prospective study on the impact of fear of falling on functional decline among community dwelling elderly women. Int $J$ Environ Res Public Health. 2017;14(5):469. doi:10.3390/ijerph14050469

10. Legters K. Fear of falling. Phys Ther. 2002;82(3):264-272.

11. Powell LE, Myers AM. The Activities-Specific Balance Confidence (ABC) scale. J Gerontol Ser A. 1995;50(1):M28-M34. doi:10.1093/ gerona/50A.1.M28

12. Bandura A. Self-efficacy mechanism in human agency. Am Psychologist. 1982;37(2):122. doi:10.1037/0003-066X.37.2.122

13. Lajoie Y, Gallagher S. Predicting falls within the elderly community: comparison of postural sway, reaction time, the Berg Balance Scale and the Activities-Specific Balance Confidence (ABC) scale for comparing fallers and non-fallers. Arch Gerontol Geriatr. 2004;38(1):11-26.

14. Dal Bello-Haas V, Klassen L, Sheppard MS, Metcalfe A. Psychometric properties of activity, self-efficacy, and quality-of-life measures in individuals with Parkinson disease. Physiother Can. 2011;63(1):47-57. doi:10.3138/ptc.2009-08

15. Guan Q, Han H, Li Y, Zhao L, Jin L, Zhan Q. Activities-Specific Balance Confidence (ABC) scale adapted for the mainland population of China. Clin Rehabil. 2012;26(7):648-655. doi:10.1177/ 0269215511427748

16. Salbach NM, Mayo NE, Hanley JA, Richards CL, Wood-Dauphinee S. Psychometric evaluation of the original and Canadian French version of the Activities-Specific Balance Confidence scale among people with stroke. Arch Phys Med Rehabil. 2006;87(12):1597-1604. doi:10.1016/j.apmr.2006.08.336

17. Costa LOP, Maher CG, Latimer J. Self-report outcome measures for low back pain: searching for international cross-cultural adaptations. Spine. 2007;32(9):1028-1037. doi:10.1097/01.brs.0000261024.27926.0f

18. Mak MK, Lau AL, Law FS, Cheung CC, Wong IS. Validation of the Chinese translated Activities-Specific Balance Confidence scale. Arch Phys Med Rehabil. 2007;88(4):496-503. doi:10.1016/j.apmr.2007.01.018

19. Parry S, Steen N, Galloway S, Kenny R, Bond J. Falls and confidence related quality of life outcome measures in an older British cohort. Postgrad Med J. 2001;77(904):103-108.

20. Graddol D. The future of language. Science. 2004;303 (5662):1329-1331. doi:10.1126/science.1096546

21. Arabic Speaking Countries List. IstiZada c; 2017. Available from: http://istizada.com/complete-list-of-arabic-speaking-countries-2014/. Accessed August 1, 2018.

22. Alghwiri AA, Alghadir AH, Al-Momani MO, Whitney SL. The Activities-Specific Balance Confidence scale and Berg Balance Scale: reliability and validity in Arabic-speaking vestibular patients. J Vestibular Res. 2015;25(5-6):253-259. doi:10.3233/VES-160568

23. Elboim-Gabyzon M, Agmon M, Azaiza F, Laufer Y. Translation and validation of the Arab version of the late-life function and disability instrument: a cross sectional study. BMC Geriatr. 2015;15(1):51. doi:10.1186/s12877-015-0046-8

24. Guillemin F, Bombardier C, Beaton D. Cross-cultural adaptation of health-related quality of life measures: literature review and proposed guidelines. J Clin Epidemiol. 1993;46(12):1417-1432.

25. Jette AM, Haley SM, Coster WJ, et al. Late life function and disability instrument: I. Development and evaluation of the disability component. J Gerontol Ser A. 2002;57(4):M209-M216. doi:10.1093/ gerona/57.4.M209
26. Ware JJE. SF-36 health survey update. Spine. 2000;25 (24):3130-3139.

27. Podsiadlo D, Richardson S. The timed "up \& go": a test of basic functional mobility for frail elderly persons. $J$ Am Geriatr Soc. 1991;39(2):142-148.

28. Shumway-Cook A, Brauer S, Woollacott M. Predicting the probability for falls in community-dwelling older adults using the timed up \& go test. Phys Ther. 2000;80(9):896-903.

29. Bland JM, Altman DG. Statistics notes: Cronbach's alpha. BMJ. 1997;314(7080):572. doi:10.1136/bmj.314.7080.572

30. Ferketich S. Focus on psychometrics. Aspects of item analysis. Res Nurs Health. 1991;14(2):165-168. doi:10.1002/nur.4770140211

31. Bland JM, Altman DG. Agreement between methods of measurement with multiple observations per individual. J Biopharm Stat. 2007;17 (4):571-582. doi:10.1080/10543400701329422

32. Bland JM, Altman D. Statistical methods for assessing agreement between two methods of clinical measurement. Lancet. 1986;327 (8476):307-310. doi:10.1016/S0140-6736(86)90837-8

33. Atkinson G, Nevill AM. Statistical methods for assessing measurement error (reliability) in variables relevant to sports medicine. Sports Med. 1998;26(4):217-238. doi:10.2165/00007256199826040-00002

34. Portney LG, Watkins MP. Foundations of Clinical Research: Applications to Practice. Upper Saddle River, NJ.Prentice Hall; 2009.

35. Terwee CB, Bot SD, de Boer MR, et al. Quality criteria were proposed for measurement properties of health status questionnaires. J Clin Epidemiol. 2007;60(1):34-42. doi:10.1016/j. jclinepi.2006.03.012

36. Moiz JA, Bansal V, Noohu MM, Gaur SN, Hussain ME. Crosscultural adaptation and psychometric analysis of the Hindi-translated Activities-Specific Balance Confidence scale. Middle East J Rehabil Health. 2016;3:1. doi:10.5812/mejrh.

37. Botner EM, Miller WC, Eng JJ. Measurement properties of the Activities-Specific Balance Confidence scale among individuals with stroke. Disabil Rehabil. 2005;27(4):156-163. doi:10.1080/ 09638280400008982

38. Cumming RG, Salkeld G, Thomas M, Szonyi G. Prospective study of the impact of fear of falling on activities of daily living, SF-36 scores, and nursing home admission. J Gerontol Ser A. 2000;55(5):M299M305. doi:10.1093/gerona/55.5.M299

39. Hatch J, Gill-Body KM, Portney LG. Determinants of balance confidence in community-dwelling elderly people. Phys Ther. 2003;83 (12):1072-1079.

40. Marques AP, Mendes YC, Taddei U, Pereira CA, Assumpção A. Brazilian-Portuguese translation and cross cultural adaptation of the Activities-Specific Balance Confidence (ABC) scale. Braz $J$ Phys Ther. 2013;17(2):170-178. doi:10.1590/S1413-355520 12005000072

41. Bogle Thorbahn LD, Newton RA. Use of the Berg Balance Test to predict falls in elderly persons. Phys Ther. 1996;76 (6):576-583.

42. Herman T, Inbar-Borovsky N, Brozgol M, Giladi N, Hausdorff JM. The dynamic gait index in healthy older adults: the role of stair climbing, fear of falling and gender. Gait Posture. 2009;29 (2):237-241. doi:10.1016/j.gaitpost.2008.08.013 


\section{Publish your work in this journal}

Clinical Interventions in Aging is an international, peer-reviewed journal focusing on evidence-based reports on the value or lack thereof of treatments intended to prevent or delay the onset of maladaptive correlates of aging in human beings. This journal is indexed on PubMed Central, MedLine, CAS, Scopus and the Elsevier
Bibliographic databases. The manuscript management system is completely online and includes a very quick and fair peer-review system, which is all easy to use. Visit http://www.dovepress.com/ testimonials.php to read real quotes from published authors. 